\title{
How cooks navigate nutrition, hunger and care in public-sector foodservice settings
}

\author{
Emma K Tsui* and Arelis Morillo \\ City University of New York School of Public Health, Lehman College, Department of Health Sciences, 250 Bedford \\ Park Boulevard West, Gillet Hall, Room 431, Bronx, NY 10468, USA
}

Submitted 29 July 2014: Final revision received 23 April 2015: Accepted 4 June 2015: First published online 2 July 2015

\begin{abstract}
Objective: To examine the perspectives and practices of cooks responsible for carrying out healthy meal programmes in publicly funded foodservice, in order to better understand what they consider to be 'good' food and where nutrition and nutritional standards fit into this conceptualization.

Design: A qualitative, exploratory study involving in-depth interviews that were conducted with cooks and their supervisors about their work practices and perspectives on providing healthy food for clients.

Setting: Participants were recruited from child-care, after-school, senior-centre and shelter settings that had participated in healthy menu training in New York City, USA. Subjects: Eighteen cooks and nine supervisors working in the aforementioned settings.

Results: The views and practices of both cooks and supervisors about what constitutes 'good' food extend beyond a purely nutritional view of goodness to include the importance of addressing hunger and clients' food preferences, among other factors. Cooks address these by interacting with clients and altering recipes and menus in a range of ways to maximize the likelihood of food consumption and enjoyment. These approaches are often, but not always, compatible with setting-specific nutritional guidelines that may be set at the national, state, local or organizational level.

Conclusions: Cooks play a key role in translating nutritional guidelines into what is served. In doing so, they engage in skilled labour and forms of care that increase the ability of public-sector foodservice to address food security and other goals, but these aspects of their work are not widely recognized.
\end{abstract}

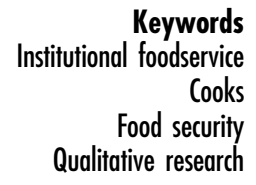

Improving institutional foodservice from a nutritional perspective has become a major component of efforts to enhance food security and address diet-related disease. Institutional foodservice can be defined in different ways $^{(1)}$, but it often refers to foods prepared for children in schools, child-care and after-school programmes; for elderly populations attending senior centres and using meal delivery programmes; and for financially impoverished populations using soup kitchens and shelters. It can also include food served in hospitals, jails, universities and the military. Our focus here is what is sometimes called the public plate ${ }^{,(2)}$, which includes food served by publicly funded or subsidized institutions that in the course of fulfilling other functions also provide food (e.g. after-school programmes) or those that provide food as a public service (e.g. home-delivered meals for seniors). From a public health perspective these are important sites as, in some cases, they provide clients with a substantial proportion of their daily nutrition over extended periods of time ${ }^{(3)}$. For example, children aged 2-4 years in governmentsubsidized child-care settings in the USA are meant to receive $60 \%$ or more of their daily energy through these sites if they are present for two meals and a snack ${ }^{(4)}$.

The FAO defines food security as that which 'exists when all people, at all times, have physical and economic access to sufficient, safe and nutritious food to meet their dietary needs and food preferences for an active and healthy life ${ }^{(5)}$. Efforts to operationalize this definition often face tensions between access, dietary needs, food preferences and how people conceptualize a healthy life for themselves. In addressing food security, institutional food and public feeding programmes worldwide must negotiate these tensions, but they do so in ways that are specific to their political, social, economic contexts, as well as the needs and preferences of the people to whom they serve food. 
In the USA, public health officials and practitioners increasingly treat institutional food as a platform for action to improve health (as well as environmental sustainability in some cases), with the focus generally on increasing the nutritional quality of food. For instance, many government-funded food programmes require that institutions receiving funding adhere to certain nutritional guidelines. Beyond this, the Centers for Disease Control and Prevention has published healthy food procurement guidelines targeted at state and local government agencies ${ }^{(6)}$ and more recently provided advice on developing health and sustainability guidelines for institutional foodservice at worksites, schools, child-care centres, hospitals, prisons and community-based organizations, among others ${ }^{(7)}$. Internationally, the WHO has identified schools and workplaces as important sites for nutrition intervention and currently, $60 \%$ of eighty-two countries surveyed by the WHO offer school lunch programmes based on national dietary guidelines ${ }^{(8)}$ (p. 75).

The preponderance of health literature on the topic of institutional food concentrates on school food. Schools have impressive reach and the appropriate focus for targeting childhood obesity, a major public health concern in the USA and elsewhere ${ }^{(9-11)}$. However, schools and other large institutional food providers are not the only type of setting that has implications for public health nutrition. Smaller and less centralized settings that do their own food preparation on site, like many child-care centres, senior centres and after-school programmes in the USA, are unique in that cooks often exert greater influence over the foods produced than in settings where preparation is more centralized.

While centralizing public foodservice might seem appealing from the perspective of standardizing nutritional offerings, centralization is not feasible for many publicsector foodservice settings and can reduce flexibility to address the needs of particular clients ${ }^{(12)}$. In decentralized settings, food workers often base the meals they serve on standardized recipes (usually shaped by nutritional regulations and standards), but the specific foods they cook and how they cook them may also be influenced by a worker's kitchen skills and knowledge about nutrition and nourishment; the resources, equipment and products at a given site; and physical and social aspects of work environments $^{(13)}$. In practical terms, however, we currently know little about these sites and the role of food workers in shaping the healthfulness of food in these and other decentralized settings.

The present study aimed to better understand workers' experiences in several decentralized institutional food settings that had adopted healthy menus and implemented an associated training programme developed by a foodservice director in New York City. This programme was designed to address the foodservice director's healthy menu principles (see Box 1) and to meet the federal Child and Adult Care Food Program guidelines for
Box 1. Six healthy menu principles taught in the healthy meals training programme

1. Eliminate the use of heavily processed foods.

2. Increase the use of fresh fruits and vegetables.

3. Increase the use of protein sources that are alternatives to meat, including beans, fish, eggs and low-fat dairy.

4. Increase the use of whole grains.

5. Promote culturally diverse and seasonal meals.

6. Promote water drinking.

reimbursement (discussed in Box 2), since many participating site-based meal programmes were partially or wholly funded via this mechanism.

Cooks participating in the training programme were expected to follow prescribed, seasonally changing standardized recipes and to attend four day-long training sessions each year. In the trainings, cooks practised several basic skills. These included learning about the six principles in Box 1, practising basic knife skills and other kitchen skills, practising making recipes from the menus and tasting these recipes. Note that when back at their sites, cooks prepared these menus largely from scratch and played only a minimal role in purchasing.

The present research study explores how cooks prepare these healthier foods and specifically examines how the idea of what is 'good' food gets interpreted and put into practice in these settings. These are important questions in the USA and beyond, particularly as we see a proliferation of nutritional standards but little attention to the perspectives and practices of workers expected to implement these new standards.

\section{Methods}

The present study involved interviews with eighteen cooks working in a range of decentralized institutional settings in New York City and with nine supervisors who oversaw these cooks. Eight centres were recruited for the study that had participated in the healthy menu training described above; four of these provided child care only, one provided after-school services only, one provided child care and after-school services, one served as a senior centre only, and one served multiple populations (child care, after-school, senior centre and shelter). At some sites we interviewed multiple cooks.* Cooks were recruited either at trainings or through information passed on by centre directors. The participation rate for cooks was

\footnotetext{
* The site serving multiple populations had the largest number of participating cooks (seven). Other sites had only one or two cooks on staff, all of whom participated. In total, we interviewed twelve child-care cooks across six sites, three senior-centre cooks across two sites, one cook working in a shelter setting, one working in an after-school programme and one who worked across multiple settings.
} 
Box 2. Brief overview of the Child and Adult Care Food Program

The Child and Adult Care Food Program (CACFP) offers reimbursement for qualifying meals and snacks served to eligible children and adults receiving care in child-care centres, family child-care homes, Head Start centres, afterschool programmes and adult-care programmes. Meal qualifications are based on US Department of Agriculture standards at the federal level ${ }^{(29)}$, but are sometimes more stringent at the state level where the programme is administered $^{(30)}$. The standards are operationalized as meal patterns of five major food groups and corresponding amounts and frequencies of each for different age groups (who are defined as having differing daily energy needs) ${ }^{(31)}$. The lunch/supper pattern for 3-5-year-olds, for instance, includes age-appropriate serving sizes (as prescribed by the US Department of Agriculture) of the following: milk, two fruits or vegetables, one grains/bread, one meat/meat alternative ${ }^{(32)}$.

Eligibility is based on a constellation of factors that are specific to the type of institution providing services. In some cases (e.g. child-care centres), a participating child's family income is assessed and meals are then reimbursed as free, reduced price or paid. In others, the income of the area in which the institution is located is assessed (e.g. after-school programmes) or the percentage of children with family incomes under $185 \%$ of the US poverty guidelines (e.g. private child-care centres) or the type of institution may qualify it for fully reimbursed meals (e.g. homeless and domestic violence shelters serving children, adult day programmes serving people who are functionally impaired or 60 years of age and older) ${ }^{(29)}$. In order to be reimbursed for these foods, centres must submit daily food production records indicating the foods used to meet the specific meal components, the amounts of these foods and the number of people served, and must document family size, income and other eligibility requirements ${ }^{(33)}$.

Table 1 Interview topics for cooks

Typical working day

Demographic information and background

Experience and tenure in the job

Job responsibilities

Perceptions of staffing and needed changes

Experiences with cooking prior to taking the job

Experiences of training in cooking and/or nutrition

Descriptions of departures from the menus

Favourite and least favourite recipes from menus

Characteristics of a good cook

Most important aspects of the job

$100 \%$ at most sites, although at the larger site serving multiple populations, it was closer to $75 \%$ due to logistical challenges and one cook who did not want to participate. With each participant, we conducted one semi-structured interview of $30 \mathrm{~min}$ to $1 \mathrm{~h}$ in length in either English or Spanish. Topics included in the cook interviews are listed in Table 1. We also had the opportunity to observe some of the cooks at work and in the periodic trainings. A basic demographic description of our sample is included in Table 2. In the current paper we focus on the experiences of cooks in child-care settings, although, where relevant, we also use insights from cooks in other settings. The study was conducted according to the guidelines laid down in the Declaration of Helsinki and all procedures involving human subjects were approved by the City University of New York Institutional Review Board at Lehman College. Written informed consent was obtained from all participants.

All interviews were audio-recorded, transcribed verbatim and translated into English when necessary. The authors analysed the interview transcripts, which totalled approximately 500 single-spaced pages of narrative data.
Table 2 Sample description of cooks ( $n$ 18), New York City, USA

\begin{tabular}{|c|c|c|}
\hline Characteristic & Value & \\
\hline \multicolumn{3}{|l|}{ Age (years) } \\
\hline Range & $17-74$ & \\
\hline Mean & $46 \cdot 2$ & \\
\hline Median & 51 & \\
\hline \multicolumn{3}{|l|}{ Years working at site } \\
\hline Range & $0.25-30$ & \\
\hline Mean & 9.9 & \\
\hline \multirow[t]{2}{*}{ Median } & 7.5 & \\
\hline & $\%$ & $n$ \\
\hline Female & $94 \cdot 4$ & 17 \\
\hline Foreign born & $66 \cdot 7$ & 12 \\
\hline Dominican Republic & $75 \cdot 0$ & 9 \\
\hline Ecuador & $16 \cdot 7$ & 2 \\
\hline Mexico & 8.3 & 1 \\
\hline Interviewed in Spanish & 38.8 & 7 \\
\hline \multicolumn{3}{|l|}{ Setting type } \\
\hline Child-care centre & $66 \cdot 7$ & 12 \\
\hline Senior centre & $16 \cdot 7$ & 3 \\
\hline After-school & $5 \cdot 6$ & 1 \\
\hline Shelter & $5 \cdot 6$ & 1 \\
\hline Multiple & 5.6 & 1 \\
\hline
\end{tabular}

We used the web-based program Dedoose (Socio Cultural Research Consultants LLC, Los Angeles, CA, USA) to help manage our data and began by reviewing the transcripts closely for themes using a process inspired by grounded theory, as described by Charmaz ${ }^{(14)}$. This led to a list of emic codes of unexpected topics introduced by research participants (e.g. addressing clients' food preferences, concerns regarding client hunger, using creativity, personal values), and we added these to a host of predetermined etic codes stemming from the interview topics (see Table 1). As is typical in many forms of qualitative data 
analysis, once we completed the list of themes, we applied these as codes to the full data set. Using the compiled excerpts for each theme, we developed analytical memos summarizing how different codes were related to one another and discussing theoretical insights.

\section{Results}

\section{'Good' food in practice: work contexts}

At the sites where we conducted the study, sites might serve a relatively set number of clients each day or a wideranging number of drop-in clients. The foodservice staff typically consisted of a head cook, an assistant cook and occasionally one or more kitchen volunteer(s). One key aspect of institutional food in smaller, more decentralized settings is that most foodservice workers in these settings are supervised directly by a centre director (overseeing all aspects of the centre's work), not by a foodservice director.

Although centre directors typically have limited to no foodservice training, they can have a strong influence on what happens in the kitchen. Directors generally reported responsibility for the following: overseeing the kitchen staff; assuring that food safety laws and prescribed menus are being followed; playing a role in food ordering; and helping to address equipment and other problems. In a few cases, supervisors spoke about going beyond these basic tasks to ask clients and staff about what foods they liked and did not like and why, and conveying this information to cooks and those designing menus. Some also discussed advocating for cooks; for instance, requesting alternative no-cook recipes that cooks could prepare on very hot days from the foodservice director who designed menus.

Almost all sites had shifted to healthier menus highlighting the six principles in Box 1 during the current centre director's tenure. While all spoke of being supportive of these menus, many noted that the shift to healthier food was important but not easy. Previously, most sites would receive menus that 'never went into detail as to what the ingredients should be, how much [there] should be. That was left up to the cooks to decide' (S104, child care). 'So if it was beef stew, they would make their version of a beef stew' (S105, after-school). As the six principles suggest, the new menus placed more emphasis on non-meat proteins and fresh produce (thus creating more work for cooks in the form of cleaning, peeling, chopping and cooking as opposed to simply opening canned fruit or heating frozen vegetables) and left supervisors sometimes feeling conflicted about giving children unfamiliar foods that they might not eat.

Another key role for directors is that they are responsible for hiring kitchen staff. Some of the characteristics directors noted that they look for in cooks included: 'joy' and 'passion' for cooking; warmth; receptiveness to new information; food safety training; experience cooking in large volumes; and experience working with the target population. One director vividly expressed an idea discussed by many supervisors:

"What stands out to me is that [the cooks] are willing to take off their aprons, and come from behind the table and work with the kids. (...) They're not just here cooking and serving food (...). If they see a kid whose shoe needs to be tied, they'll help a kid out. They'll see that a kid is hungry (...) they'll make sure that that kid has an extra portion. (...) I like that about them. Being in this community centre, you know, it would bother me if they were trying to stick to the script. That doesn't work for me here. We wear many hats.' (S105, after-school)

\section{'Good' food in practice: the role of cooks}

One of the primary ways that we tried to understand how 'good' food works in practice at these sites was to examine situations in which cooks deviated from the prescribed healthy menus. The most common of these situations were: (i) the site had unexpectedly run out of an ingredient or did not have as much as was needed; (ii) an order had not come in on time; and (iii) according to cooks, the recipe needed to be changed to ensure that clients would consume it. This last point, which is the only reason cooks cited for actively initiating changes, highlights the cooks' strong desire to ensure that clients will eat what they cook. Some cooks described testing recipes before serving them. As one cook said:

'I go home and I'll try a recipe and see how it tastes. Because sometimes the way they want us to cook it, it's just like okay, these kids are not gonna eat this.' (C104, after-school)

She explained that these recipe tests also allow her to experiment with minor alterations to the recipe to improve uptake among clients.

As we have reported in a previous article ${ }^{(13)}$, the forms of recipe modification described above appear to be somewhat common. In an earlier phase of the study, we conducted structured food preparation observations at three child-care sites. Our observational data, which involved twelve meals and the preparation of thirty-one unique dishes, indicated that cooks substituted alternative ingredients and cooking techniques in eight dishes, approximately $25 \%$ of all dishes in this small sample. Data were collected while cooks were being openly observed by a trained research assistant, so it is likely that these are underestimates of the actual modifications taking place.

Almost all cooks participating in interviews expressed that their first step before making something other than what is on the menu is to consult with their supervisors. Most cooks reported that supervisors almost always agree to their suggestions, usually on the condition that they attempt to address the six principles and comply with the 
basic meal pattern. Some cooks mentioned that if a particular recipe is not popular with clients (e.g. they have cooked it a few times and noticed that few clients are eating it), they will either contact or have the supervisor contact the person designing the menus to give feedback and ask for advice.

If a full meal has to be changed because of missing ingredients, cooks most often reported first trying to substitute whole meals with other meals that are already approved. As one cook said:

'I basically look through my menus and see what I do have that I know I'm allowed to cook, and I just use one of those items.' (C106, child care)

When this is not possible, cooks described resorting to what they called 'back-up recipes'. These include recipes or meals that address the intended meal pattern, but that often use shelf-stable or frozen ingredients that can be kept on hand. Another type of 'back-up recipe' mentioned by a cook was a recipe that she uses when specific children at her site do not eat anything from the day's planned menu. In this case, this cook said:

'I will send them a cookie, or cheese, or whatever there is to replace their meal; or I make a vegetable soup. I find a way to make them eat something that they like.' (C116, child care)

As noted previously, many changes were made as a way to get clients (often children, in particular) to eat items that cooks and directors feared they might not be willing to eat otherwise. Changes cooks made to encourage clients to eat included taking out certain ingredients incorporated into an item and serving them on the side (e.g. serving corn on the side rather than inside a quesadilla), disguising certain ingredients that clients might not like (e.g. puréeing beans that make up a layer in a casserole) and making dishes seem more pleasing or familiar when possible (e.g. toasting sandwiches as is done at popular sandwich shops or baking macaroni and cheese to give it a crunchy top). In two cases, cooks mentioned adding meat to a dish that already had a non-meat protein in it. For instance, one cook told us that she added chicken to a dish that involved egg as its primary protein because she felt it did not have enough protein for children to be a 'full meal' (C116, child care). Another cook added ground turkey to a bean-based chilli recipe after receiving complaints from clients and staff that the dish was missing meat (C104, after-school). These kinds of changes were often not approved by supervisors in advance.

\section{'Good' food beyond nutrition}

As the previous sections suggest, the views of both cooks and supervisors about what constitutes 'good' food goes beyond a purely nutritional view of goodness. As the afterschool supervisor indicated, these cooks are indeed moving beyond simply implementing a set of menus and healthy cooking principles (their basic duties) to a position from which they care, surprisingly deeply in many cases, about whether their food is eaten and whether it pleases clients. We might ask how they come to care about this and why.

Our data suggest two answers to these questions. First, many cooks believe that centres are one of clients' primary sources of food and nutrition. As one cook said, 'You know that a child may not get enough to eat at home' (C101, child care). Another cook expressed her distress about an unsuccessful snack recipe in terms of hunger by saying:

'Everything came back. And it was snack, [so] there was nothing I could give them to make up for that, because it's time to go home. When a lot of these kids go home, they don't eat.' (C106, child care)

A second reason why cooks care about whether their food is eaten has to do with pride in their work. This pride was oriented around producing foods that clients liked, would eat and did not throw away. Multiple cooks described checking the garbage after meals to see what was not being eaten. As one said:

'I always check the garbage. And I say, hold on, they really ate it! (...) Because if they don't like something, and I notice it, I call [my supervisor]. I don't like to waste food.' (C106, child care)

Another put a slightly different spin on this point by saying:

'As a cook you don't wanna waste your time. You don't like to see the food ending [up] in the garbage.' (C110, child care)

As the difference between these two quotes lightly suggests, some cooks were more motivated by the reactions from clients to the food and others were more focused on the technicalities of producing food. The vast majority fell into the former category. This may seem like a mere corollary of the idea that cooks are concerned about client hunger and that producing foods that are pleasing facilitates cooks' and organizations' ability to address hunger. However, our data suggest that there is an important social dimension of this dynamic as well. When describing a more labour-intensive recipe, one of the cooks surprised us by saying about the recipe, 'I love doing it, too, because [the clients] really like it' (C106, child care). The goal may indeed be to get clients to eat, but not without pleasure. As another cook said:

'I get very happy and very excited when I cook something and they actually like it. Like I try to tweak it and make it just a little better, or how they would like it.' (C104, after-school)

It turns out that this is not a one-way social dynamic. Children often seemed to know the cooks by name and to 
speak with them directly about food, which some cooks reported enjoying immensely. One head cook said:

'Because I go to the classrooms, these kids, if they see me in the street, [they say] "Hi Ms Smith, hi Ms Smith, hi!" Or, "that's the cafeteria lady!". (C101, child care; pseudonym used)

The rewards associated with cultivating a social role that is enacted and recognized outside the kitchen were further underscored by a cook at a senior centre who said that food is a mechanism for showing clients 'that you care about them'. She told a story demonstrating how she uses food and conversation to keep seniors coming to the site consistently. In her words:

'I say, "Don't stay home. Keep coming out to the centre. You'll see because you'll feel better, because your husband has gone on, and you're still here and he would want you to go on".'

On what she gets out of this, she said:

'Just them seeing me here, they know that they gonna have a good lunch, a good breakfast. And I would say, me being around them, you know, it, it makes me feel good as a senior as well as the cook here.' (C105, senior centre)

\section{Discussion}

Historically, publicly funded foodservice has functioned in many places as a way - in part at least - to provide sustaining energy to populations that lack access to such resources $^{(10,15,16)}$. Grafting nutritional regulations and standards on to publicly funded foodservice programmes has sought to raise the quality of food and sometimes served to improve the balance of nutrients in menu offerings, especially in recent decades in response alarming statistics on diet-related disease in the USA and globally ${ }^{(6,7)}$. As institutional food systems accelerate their efforts to improve the nutritional quality of their offerings, emphasis has been on compliance with these nutritional standards and often primarily through more attentive purchasing practices.

These are important steps, but in focusing on these, we have neglected those complex dynamics taking place between purchasing and what ends up on the plate. In many settings, cooks play a key role in translating nutritional guidelines into what is served, sometimes taking into account what might get eaten or not. With investments in training and the design of healthy menus, cooks in the present study largely sought to remain true to the menus, to the letter when possible and in spirit in almost all cases. However, they carried out their work of preparing these menus, making substitutions in the case of logistical issues and experimenting with recipes, with a keen eye trained on clients' food preferences and a sense that they should eat 'something' (C116, child care), values that are not explicitly recognized in American population-level nutrition guidelines like those of the Child and Adult Care Food Program discussed here.

These practices reflect the cooks' close attention to the clients who come to their centres on a daily basis from surrounding neighbourhoods (often the same neighbourhoods where the cooks themselves live) and who praise or throw away their food. They may also reflect the forms of knowledge and experiences, particularly of food insecurity, carried by cooks from their home countries and pasts into the kitchens where they work. These practices thus also reflect the relationship between cooks and clients in these settings. Likely without realizing it, in doing this work in this way, cooks help their organizations address the FAO's definition of food security presented earlier, which nutritional guidelines alone do not. Cooks correct our generalized concern about overeating in the USA to reflect their particular settings, where the problem of not eating enough may be more common ${ }^{(17,18)}$.

But more is being achieved here than food security alone. For cooks, there is a social identity in this work that many of them embrace. This identity is demonstrated through their pride in their work, their attention to the menus and their attention to the clients' preferences and needs. Pride is well documented as a motivation among restaurant chefs ${ }^{(19)}$ (p. 179) and yet it is worth mentioning that this can be a strong motivator among institutional cooks also. This work also gives them an opportunity to practise what Annemarie Mol, who has written about food in nursing homes in the Netherlands, calls 'nourishing care'. 'Nourishing care' provides the opportunity for multiple 'goods' to be conveyed, but she notes that 'the relations between such goods can be strikingly complex ${ }^{,(17)}$ (p. 216). Goods that cooks may balance as they make and serve recipes include: addressing hunger, pleasure and the development and maintenance of social relationships among themselves and with clients and supervisors; addressing the whole person who exists both within and outside the centre; and to some lesser degree, addressing economics (largely through seeking to reduce food waste). The constant, shifting calculations that go into the balancing of these goods are essential to the success of these organizations in addressing not only nutrition and food insecurity, but also in carrying out their social missions more broadly.

Preserving the potential for pride and nourishing care in these settings depends not only on training cooks and supervisors to deliver nutritionally sound foods and menus (and supporting this work with resources and infrastructure), but also, critically, on allowing them autonomy and space for what Mol has called 'tinkering' or 'attentive experimentation $^{\text {(20) }}$ (p. 13). For cooks, this means allowing them to continue to modify recipes and provide feedback on what works in terms of getting eaters to 
engage with unfamiliar foods and allowing them opportunities to interact with clients. Currently, in the settings studied, there is a unique feature of the healthy menus programme that creates a certain degree of recognition of these insights. The foodservice director who designs the menus and trainings is in frequent contact with cooks and supervisors about what works and does not in their settings. She attends almost as much to the details of what makes menus work in particular settings as to the meal component accounting required for reimbursement by the Child and Adult Care Food Program. Cooks thus have someone available to them who values their opinions and can change menus accordingly, as well as someone who values both the health- and pleasure-related dimensions of food. It is this function, not present in many public foodservice organizations, which recognizes attentive experimentation and honours it as something of which cooks can be proud.

Although little international literature on the work of cooks in publicly funded foodservice currently exists, there are many aspects of the present analysis that are potentially applicable to other countries. For instance, the need to alter what is served based on logistical challenges is likely to be a common occurrence throughout systems internationally, especially where foodservice sites are more decentralized and/or in systems with limited resources and infrastructure. Research suggests that decentralized systems of public feeding (particularly school feeding) are common in developing countries ${ }^{(21)}$ and that even large, well-developed systems like that of school food in the UK may be heading towards greater decentralization $^{(22)}$. As in our study, implementing healthy menu training in these settings might offer cooks additional skills to draw on when improvisation is required. Like the cooks in our study, we imagine that public-sector cooks internationally also have the potential to translate nutritional guidance into food experiences that reflect the particular needs of their clients. Whether it would be fruitful to encourage experimentation among cooks in other countries to achieve goals like food security depends on how public foodservice settings are structured and on the degree, type and opportunities for communication between cooks and clients, as well as between cooks and supervisors.

One factor that may be unique to the specific settings studied and to higher-resource countries like the USA is the extent to which cooks and menu designers perceive a need to cater to client tastes. Even the mere provision of institutional meals is not a given in low- and middle-resource countries, which provide school meals to only $18 \%$ and $49 \%$ of students, respectively ${ }^{(21)}$. However, even in lower-resource settings like Guyana, successful school feeding schemes have involved community participation, nutritious meal preparation training and take into account local food preferences ${ }^{(21)}$. Community participation in the design and implementation of school feeding programmes internationally is recommended by the World Bank and scholars, partially as a way of addressing local food preferences ${ }^{(23,24)}$.

It is important to contextualize our interpretation of these findings with a brief discussion of the study's strengths and weaknesses. This research was conducted with a small number of cooks and sites in New York City. Thus, the ways that public foodservice systems in other places are structured at both the micro (day-to-day supervision and contact with clients) and the macro (government oversight and policies, funding, centralization of food production, etc.) levels strongly shape how relevant our findings would be in these settings. In keeping with commonly used qualitative research principles ${ }^{(25)}$, we look not to the concept of generalizability to understand how these findings extend to other locations, but rather to transferability, in which the onus is on readers of the research to interpret the potential utility of the findings for their own contexts. Additionally, while we recognize that our sample includes a larger concentration of cooks from child-care sites than from other types of site, we see the insights from other types of site as enriching the study's findings. Still, it bears noting that we collected data from only one cook at some types of site and that the participants in our study are not representative of all public-sector foodservice cooks.

One of the strengths of the present study is that it integrates multiple techniques frequently used in qualitative research for maximizing the quality and trustworthiness of data analysis ${ }^{(26)}$. Having two people participate in data collection and analysis allowed us to triangulate our interpretations of the data, a process best conducted by researchers from diverse backgrounds; in this case, a $\mathrm{PhD}$ level researcher who is a non-native Spanish speaker, and a master's level student who is a native Spanish speaker and who was raised in the same country as many of our participants. Additionally, after our initial analysis, we presented a summary of our findings and interpretations to the majority of cooks and supervisors who participated in the study (a form of respondent validation), as well as to numerous other cooks working in similar settings who were not part of the study. Our findings were challenged and enriched by these feedback sessions.

\section{Conclusion}

To our knowledge, the tinkering that institutional cooks may do in the kitchen to help translate nutritional guidelines into food security and 'nourishing care' is rarely discussed or documented. Future research might explore how common recipe modification is, what forms it takes and what motivates it across a greater variety of institutional food settings, as well as how local communities come to have input into public feeding in countries with different public foodservice systems. Looking closely at 
staffing structures and different levels and types of cook training could be important in identifying how different conditions shape cooks' perspectives and practices. Building on work conducted in schools ${ }^{(27)}$, researchers could also examine what forms of modification and experimentation take place in more centralized settings.

In terms of public health nutrition practice, if improvisation and the multiple goods that food in these settings can offer were more explicitly recognized, cooks, supervisors and foodservice directors might be able to more systematically assess what is working to address food security. Such an approach might also incentivize these groups to refine what they are trying to achieve through their food programmes (e.g. provide familiar foods, expose clients to new foods) and to more explicitly pursue this. Institutional foodservice leaders who guide cooks based on an understanding that nutritional guidelines exist within a complex landscape of 'goods' (in Mol's sense) are likely to have greater success than others in making this leap beyond mere compliance.

Finally, while the current paper generally highlights the benefits that can be achieved through a caring practice of food provision, the ways in which these practices reverberate in the lives of clients and cooks may have less positive aspects as well. For instance, although the study shows experimentation being used to achieve health and social goals, it is also possible that recipe modification could have undesired implications for client health and nutritional well-being. Additionally, cooks may find that they are doing more and different work than they are being compensated for. Particularly in the USA, the skilled nature of this 'relational work' ${ }^{(28)}$ is rarely recognized in financial compensation for public foodservice jobs, which are persistently low paid. The forms of recognition recommended above might help to create a shift in social perceptions of these jobs, but in order to meaningfully encourage 'nourishing care' in these settings, the work must be valued economically as well.

\section{Acknowledgements}

Acknowledgements: The article was improved by helpful critiques and comments from Janet Poppendieck, May May Leung, Jonathan Deutsch, Kimberly Libman, and attendees and panellists who were part of the 2014 Association for the Study of Food and Society Conference's 'Digging into "Good" Food' panel. The authors would also like to express their sincere gratitude to the cooks and supervisors who shared their valuable time and insights with them. They are grateful as well to the organizations employing these staff for facilitating this work and for allowing staff members the time to participate; and to Stefania Patinella for her support and critical eye throughout the research process. Financial support: This research was supported by a PSC-CUNY grant through the
City University of New York (grant number 66549-0044). PSC-CUNY had no role in the design, analysis or writing of this article. Conflict of interest: None. Authorship: E.K.T. formulated the research questions, designed the study, developed study partnerships, and led the processes of data collection, analysis and writing. A.M. collaborated in the processes of data collection and analysis, and provided feedback on the article. Ethics of human subject participation: The City University of New York Institutional Review Board at Lehman College provided ethical review and approval for this study. Written informed consent was obtained from all participants.

\section{References}

1. Tsui EK (2014) Public institutional foodservice. In Encyclopedia of Food and Agricultural Ethics. Brussels: Springer.

2. Morgan K (2006) School food and the public domain: the politics of the public plate. Polit $Q 77,379-387$.

3. Food Bank for New York City (2007) NYC Hunger Safety Net 2007: A Food Poverty Focus. New York: Food Bank for New York City.

4. Institute of Medicine (2011) Child and Adult Care Food Program: Aligning Dietary Guidance for All. Washington, DC: The National Academies Press.

5. Food and Agriculture Organization of the United Nations (1996) Rome Declaration of World Food Security and World Food Summit Plan of Action. Rome: FAO.

6. Centers for Disease Control and Prevention (2011) Improving the Food Environment Through Nutrition Standards: A Guide for Government Procurement. Atlanta, GA: US Department of Health and Human Services, Centers for Disease Control and Prevention, National Center for Chronic Disease Prevention and Health Promotion, Division for Heart Disease and Stroke Prevention.

7. Kimmons J, Jones S, McPeak HH et al. (2012) Developing and implementing health and sustainability guidelines for institutional food service. Adv Nutr 3, 337-342.

8. World Health Organization (2013) Global Nutrition Policy Review: What Does It Take to Scale Up Nutrition Action? Geneva: WHO.

9. Fung C, McIsaac J-LD, Kuhle $S$ et al. (2013) The impact of a population-level school food and nutrition policy on dietary intake and body weights of Canadian children. Prev Med 57, 934-940.

10. Devi A, Surender R \& Rayner M (2010) Improving the food environment in UK schools: policy opportunities and challenges. J Public Health Policy 31, 212-226.

11. Briefel RR, Crepinsek MK, Cabili C et al. (2009) School food environments and practices affect dietary behaviors of US public school children. $J$ Am Diet Assoc 109, 2 Suppl., S91-S107.

12. Public Plate Report Working Group (2014) The Public Plate in New York City: A Guide to Institutional Meals. New York: New York City Food Policy Center at Hunter College.

13. Tsui EK, Deutsch J, Patinella S et al. (2013) Missed opportunities for improving nutrition through institutional food: the case for food worker training. Am J Public Health 103, e14-e20.

14. Charmaz K (2001) Grounded theory. In Contemporary Field Research: Perspectives and Formulations, pp. 335-352 [RM Emerson, editor]. Prospect Heights, IL: Waveland Press, Inc.

15. North Carolina Department of Health and Human Services, Nutrition Services Branch (2014) History of the Child and Adult Care Food Program. http://www.nutritionnc.com/ snp/historyc.htm (accessed June 2014). 
16. Poppendieck J (2010) Free for All: Fixing School Food in America. Berkeley, CA: University of California Press.

17. Mol A (2010) Care and its values: good food in the nursing home. In Care in Practice: On Tinkering in Clinics, Homes and Farms, pp. 215-234 [A Mol, I Moser and J Pols, editors]. Bielefeld: Transcript Verlag.

18. Cohen JFW, Richardson S, Austin SB et al. (2013) School lunch waste among middle school students: nutrients consumed and costs. Am J Prev Med 44, 114-121.

19. Fine GA (1996) Kitchens: The Culture of Restaurant Work. Berkeley, CA: University of California Press.

20. Mol A, Moser I \& Pols J (2010) Care: putting practice into theory. In Care in Practice: On Tinkering in Clinics, Homes and Farms, pp. 7-26 [A Mol, I Moser and J Pols, editors]. Bielefeld: Transcript Verlag.

21. World Food Programme (2013) State of School Feeding Worldwide 2013. Rome: WFP.

22. Dimbleby H (2014) Free school meals: ready, steady, build a kitchen. The Guardian, 14 January. http://www.theguardian. com/education/2014/jan/14/hot-school-meals-for-infants-willhelp-academic-progress (accessed June 2015).

23. Bundy D, Burbano C, Grosh M et al. (2009) Rethinking School Feeding: Social Safety Nets, Child Development, and the Education Sector. Washington, DC: The World Bank.

24. Otsuki K (2011) Sustainable partnerships for a green economy: a case study of public procurement for home-grown school feeding. Nat Resour Forum 35, 213-222.

25. Lincoln YS \& Guba EG (1985) Naturalistic Inquiry. Newbury Park, CA: SAGE Publications, Inc.

26. Mays N \& Pope C (2000) Qualitative research in health care. Assessing quality in qualitative research. BMJ 320, $50-52$.

27. Feldman C, Briceno-Pinar EA, Konas DW et al. (2009) A laboratory analysis of total fat content and an examination of portion size of foods served in four New Jersey public middleschool foodservice operations. J Foodserv 20, 264-274.
28. Duffy M (2005) Reproducing labor inequalities: challenges for feminists conceptualizing care at the intersections of gender, race, and class. Gender Soc 19, 66-82.

29. Food Research and Action Center (2009) Fact Sheet: Child and Adult Care Food Program (CACFP). http://frac.org/wpcontent/uploads/2009/09/cncacfp.pdf (accessed June 2015).

30. Food Research and Action Center (n.d.) Improving CACFP in New York State through Education and Policy Change. Washington, DC: Food Research and Action Center; available at https://urldefense.proofpoint.com/v2/url?u=http-3A_frac.org _pdf_cacfp-5Fcase-5Fstudy-5Fnew-5Fyork-5Fstate-5Fpolicy-5Fc hange.pdf\&d=AwIFAg\&c=uxRm7bTqKzXs8e $5 \mathrm{WpHvdhQ \& r=8}$ ig-N-4EpC1bvzwH2aD-k17gK_PWlm8sZJ2TlYikeh0\&m=LEZG 2m6ARiGNYswqzSHtDCvp7MgDxI9DoJMlkl0IOYY\&s=x_X v0DzWIpfRv4qW1Y4u8VpF9XlzzpGBlJxwYsOwPTE\&e=

31. US Department of Agriculture, Center for Nutrition Policy and Promotion (2013) USDA Food Patterns. http://www. cnpp.usda.gov/USDAfoodpatterns.htm (accessed June 2014).

32. US Department of Agriculture, Food and Nutrition Service (2015) Child and Adult Care Food Program Child Care Meal Patterns. https://urldefense.proofpoint.com/v2/url?u=http-3 A__www.fns.usda.gov_cacfp_meals-2Dand-2Dsnacks\&d=

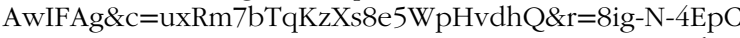
1bvzwH2aD-k17gK_PWlm8sZJ2TlYikeh0\&m=LEZG2m6AR iGNYswqzSHtDCvp7MgDxI9DoJMlk10IOYY\&s=DeJT3P_i 8GVv2SHmIW50Fd0WdwGww5amim72gMYkGs0\&e= https://urldefense.proofpoint.com/v2/url?u=http-3A www.fns.usda.gov_cacfp_meals-2Dand-2Dsnacks\&d=AwI

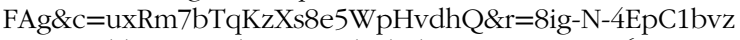
wH2aD-kl7gK_PWlm8sZJ2TlYikeh0\&m=LEZG2m6ARiGNY swqzSHtDCvp7MgDxI9DoJMlk10IOYY\&s=DeJT3P_i8GVv2 SHmIW50Fd0WdwGww5amim72gMYkGs0\&e= (accessed June 2015).

33. New York State Department of Health (2011) The Child and Adult Care Food Program (CACFP). https://www.health.ny. gov/prevention/nutrition/cacfp/faq.htm (accessed June 2014). 